Polymer Journal, Vol. 39, No. 11, pp. 1177-1184 (2007)

(C)2007 The Society of Polymer Science, Japan

\title{
Synthesis and Swelling/De-swelling Behavior of Core-Shell Type Gel Consisting of Two Different Poly $(N$-alkylacrylamide) Gel Layers
}

\author{
Takashi IIZAwA, ${ }^{\dagger}$ Akihiro TERAO, Machiko OHUCHIDA, \\ Yoshinobu MATSUURA, and Yukio ONOHARA \\ Department of Chemical Engineering, Graduate School of Engineering, Hiroshima University, \\ 1-4-1 Kagamiyama, Higashi-Hiroshima 739-8527, Japan
}

(Received May 18, 2007; Accepted August 13, 2007; Published September 26, 2007)

\begin{abstract}
When poly(acrylic acid) gel-1,8-diazabicyclo-[5,4,0]-7-undecene salt (DAA) was placed in $N$-methyl-2-pyrrolidone containing an excess of alkylamine and triphenylphosphine, selective amidation occurred from the surface to give the corresponding DAA-poly( $N$-alkylacrylamide) (PNAA) core-shell type gel, consisting of an unreacted DAA core and a quantitatively amidated shell layer. Further amidation of the DAA-PNAA core-shell type gel with a second alkylamine afforded a novel core-shell type gel consisting of two PNAA layers: PNAA(2) and PNAA(1). Thermal properties of the resulting core-shell type gels, such as swelling/de-swelling behavior, were measured in water at various temperatures. The resulting cylindrical PNAA(2)-PNAA(1) core-shell type gels were resistant to marked deformation caused by swelling/de-swelling because of their axial symmetry. In contrast, the semi-cylindrical double-layer gel prepared from the cylindrical poly( $N$-isopropylacrylamide)-poly( $N$ - $n$-propylacrylamide) core-shell type gel was markedly bent in water at temperatures between the lower critical solution temperatures of both layers. [doi:10.1295/polymj.PJ2007044]

KEY WORDS Thermosensitive Gel / Poly $(N$-alkylacrylamide) Gel / Amidation / Core-shell Type Gel / Swelling / De-swelling / Semi-cylindrical Gel /
\end{abstract}

Poly $(N$-alkylacrylamide) (PNAA) gels containing C2-C3 alkyl groups are thermosensitive with lower critical solution temperatures (LCST). ${ }^{1}$ They swell in water at temperatures below the LCST and de-swell at temperatures above the LCST. The LCST varies, depending on the alkyl groups. Since $\operatorname{poly}(\mathrm{N}$-isopropylacrylamide) (PNIPA) gel has an LCST at a temperature slightly higher than room temperature, ${ }^{2}$ it can be used in a variety of applications such as extraction, ${ }^{3}$ absorption, ${ }^{4}$ drug-delivery, ${ }^{5}$ and enzyme immobilization. ${ }^{6}$ Also, synthetic techniques for particles, ${ }^{7}$ porous gels, ${ }^{8}$ graft polymers, ${ }^{9}$ and comb polymers ${ }^{10}$ that are suitable for use in applications have been developed. However, conventional synthetic techniques are not always available for new applications of PNAA because the only known synthetic methods are based on the radical polymerization of the corresponding monomers. Another synthetic method is direct condensation of poly(acrylic acid) (PAA) with an alkylamine, using an activating agent. Activating agents and reaction systems for amidation have been developed for the direct polycondensation of dicarboxylic acids with diamines. ${ }^{11}$ However, the application of these methods to the synthesis of thermosensitive polymers has been described in only a few papers. $^{12}$

In recent studies, we reported a new synthetic method of core-shell type gels by the heterogeneous reac- tion of the PAA-1,8-diazabicyclo-[5,4,0]-7-undecene (DBU) salt (DAA) with reagents, such as alkyl halides $^{13}$ and alkylamines, ${ }^{14}$ and on the acetylation of poly(2-hydroxylethyl acrylate) gel. ${ }^{15}$ When triphenylphosphite (TPP) was used as the activating agent, the amidation of DAA with alkylamine started from the surface of the gel, yielding a new DAA-PNAA coreshell type gel that consisted of an unreacted DAA core gel and a chemically reacted PNAA shell (Figure 1, Figure 2). ${ }^{14}$ Finally, the reaction afforded PNAA gel. Since the unreacted DAA core in the core-shell type gel is the same as the original DAAA, it can react with various reagents to give a wide variety of coreshell type gels. For example, neutralization of DAAPNAA type core-shell type gels with acetic acid produced the corresponding PAA-PNAA type core-shell

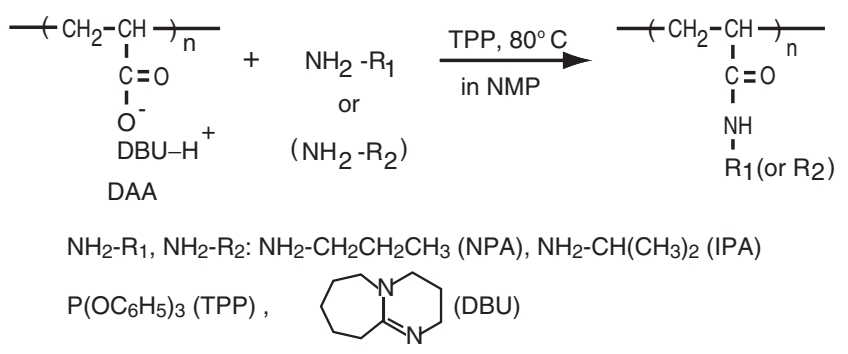

Figure 1. Synthesis of a PNAA gel via the reaction of DAA with NPA and IPA.

${ }^{\dagger}$ To whom correspondence should be addressed (Tel: +81-82-424-7711, Fax: +81-82-424-5494, E-mail: tiizawa@ hiroshima-u.au.jp). 


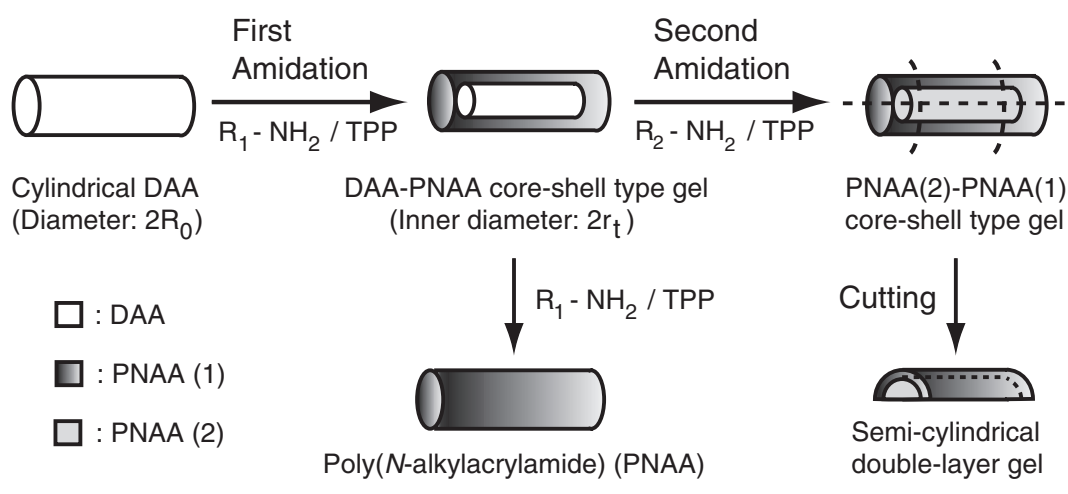

Figure 2. Synthesis of a PNAA gel, DAA-PNAA core-shell type gel, PNAA(2)-PNAA(1) core-shell type gel, and semi-cylindrical, double-layer gel.

type gels. ${ }^{14 \mathrm{~b}, \mathrm{~d}}$ Although seed emulsion polymerization has been well-known for the synthesis method of fine core-shell type particles, ${ }^{16}$ this heterogeneous amidation possess great advantages over the polymerization method as follows; since the resulting core-shell type gels have essentially the same main chain structure and shape as the original DAA samples, 1) a desired shape and size of core-shell type gel can be prepared as well as fine particles, and 2) it has a defined structure-a continuous network and a boundary between both layers. These advantages prompt us to design a functional core-shell type gel which can hardly be prepared by the polymerization of the corresponding monomers.

This paper reports the successful synthesis of novel cylindrical core-shell type gels, consisting of two different PNAA layers, PNIPA gel and poly $(N-n$-propylacrylamide) (PNNPA) gel layers as PNAA(2) and PNAA(1), by further amidation of the DAA-PNAA core-shell type gels with another alkylamine, using TPP as the activating agent (Figure 2). Furthermore, we propose the preparation of sem-cylindrical, thermosensitive, double-layer gels; the long cylindrical core-shell type gels are cut into two halves. The unique structure- a continuous network and a boundary between both layers is of interest because the thermosensitive behavior may differ between the layers, and the structure may have strong resistance against destruction on the boundary.

\section{EXPERIMENTAL}

\section{Materials}

Acrylic acid and solvents were distilled prior to use. Commercial alkylamines such as $n$-propylamine (NNA) and isopropylamine (IPA) were used as purchased. $N, N^{\prime}$-methylenebisacrylamide (MBAA), DBU, and TPP were used without further purification. Cylindrical DAA (diameter: about 5.3, length: about $20 \mathrm{~mm}$ ) was prepared via a two-step procedure, in- volving the copolymerization of acrylic acid with $0.5 \mathrm{~mol} \%$ of MBAA in Teflon tubes (internal diameter: $6 \mathrm{~mm}$ ), and neutralization of the resulting gel with excess DBU in methanol, as described previously. ${ }^{14 a}$ The samples were washed extensively with methanol in a Soxhlet extractor, and then dried in vacuo at $60^{\circ} \mathrm{C}$ to a constant weight. Nonporous cylindrical PNIPA gels (PNIPA-2) were prepared by the copolymerization of NIPA with $0.5 \mathrm{~mol} \%$ of MBAA in Teflon tubes (internal diameter: $6 \mathrm{~mm}$ ) at a temperature below $5{ }^{\circ} \mathrm{C}$ according to Kayaman's paper. ${ }^{17}$ Porous spherical PNIPA gel (PNIPA-3) containing 2 mol $\%$ MBAA prepared by sedimentation polymerization was used. ${ }^{7 \mathrm{~b}}$

\section{Synthesis of DAA-PNAA core-shell type gels}

A typical synthesis of DAA-PNAA type core-shell type gels was as follows. $200 \mathrm{~mL}$ of a mixed solution of TPP $\left(1.0 \mathrm{~mol} \mathrm{~L}^{-1}\right)$ and NPA $\left(2.0 \mathrm{~mol} \mathrm{~L}^{-1}\right)$ in NMP was charged into a $300 \mathrm{~mL}$ Erlenmeyer flask in an $80^{\circ} \mathrm{C}$ water bath. Dozens of DAA samples $\left(2 R_{0}=\right.$ $5.3 \mathrm{~mm}$ ) were soaked in this solution for $200 \mathrm{~min}$ until the thickness of the shell layer $\left(1-r_{t} / R_{0}\right)$ reached 0.30 , where $2 R_{0}$ and $2 r_{t}$ are the external diameters of the original DAA sample and core after $t=t \mathrm{~min}$, respectively. The gels were taken out of the solution and put in a large quantity of methanol to terminate the reaction. The resulting G-2, DAA-PNNPA coreshell type gels were washed with methanol in a Soxhlet extractor. They were dried in vacuo at $60^{\circ} \mathrm{C}$ to a constant weight.

Synthesis of PNAA(2)-PNAA(1) core-shell type gels

A typical synthesis of PNAA(2)-PNAA(1) coreshell type gels was as follows. $200 \mathrm{~mL}$ of a mixed solution of TPP $\left(1.0 \mathrm{~mol} \mathrm{~L}^{-1}\right)$ and IPA $\left(2.0 \mathrm{~mol} \mathrm{~L}^{-1}\right)$ in NMP was charged into a $300 \mathrm{~mL}$ Erlenmeyer flask in an $80^{\circ} \mathrm{C}$ water bath. Dozens of G-2 samples were soaked in this solution for $24 \mathrm{~h}$. The gels were taken out of the solution and placed in a large quantity of 
methanol. The resulting PNAA(2)-PNAA(1) coreshell type gels were washed with a dilute acetic acid solution in methanol for $1 \mathrm{~d}$, and then with methanol in a Soxhlet extractor for $1 \mathrm{~d}$. They were dried in vacuo at $60^{\circ} \mathrm{C}$ to a constant weight. The gel was dipped in triethylamine solution in methanol (10 $\mathrm{mmol} \mathrm{L}{ }^{-1}, 25 \mathrm{~mL}$ ) at room temperature for $24 \mathrm{~h}$. Free carboxylic acid in the gel was determined by neutralization titration of the filtrate with $0.01 \mathrm{~mol} \mathrm{~L}^{-1} \mathrm{HCl}$ solution. However, it was not detected.

\section{Measurement of IR spectra of PNNPA-PNIPA core- shell type gels}

A PNNPA-PNIPA core-shell type gel sample was swollen in water at $25^{\circ} \mathrm{C}$, and was cut into round slices. The swelled PNIPA shell layer was peeled off to divide into two groups, the swelled shell layer and unswelled core. After drying, every group was grinded down with an agate mortar. IR spectra $(\mathrm{KBr})$ of the grinded powders were obtained using a Perkin Elmer model IR-700 spectrophotometer.

Measurement of Amidation Rate of DAA and DAAPNAA core-shell type gels with Alkylamine

In a typical amidation of dried G-2, a mixed solution $(50 \mathrm{~mL})$ of IPA $\left(2.0 \mathrm{~mol} \mathrm{~L}^{-1}\right)$ and TPP $(1.0$ $\mathrm{mol} \mathrm{L}^{-1}$ ) in $N$-methyl-2-pyrrolidone (NMP) was charged into a $50 \mathrm{~mL}$ cylindrical cell in an $80^{\circ} \mathrm{C}$ water bath. Cylindrical DAA was immersed in this solution. The $R_{0}$ and $r_{t}$ were determined at $10 \mathrm{~min}$ intervals using a digital video camera (Sony, DCR-TRV950, image of $640 \times 480$ pixels).

\section{Measurement of Swelling/De-swelling Rate}

A sample was placed in a $50 \mathrm{~mL}$ cylindrical cell at the desired temperature. The change in external radius $\left(R_{t}^{\prime} / R_{D}^{\prime}\right.$ or $\left.R_{t}^{\prime} / R_{0}^{\prime}\right)$, where $2 R_{D}^{\prime}, 2 R_{0}^{\prime}$, and $2 R_{t}^{\prime}$ are the external diameters of the dried gel, the gel stored in water at $50^{\circ} \mathrm{C}$, and the gel swollen or de-swollen after $t=t$ min, respectively, was recorded using the digital video camera system described above.

\section{Measurement of Equilibrium Swelling Ratio}

A sample was immersed in water at the desired temperature (the initial temperature was $50^{\circ} \mathrm{C}$ ). The equilibrium swelling ratio was measured using a previously reported method. ${ }^{15 \mathrm{~b}}$ The relationship (Ws + $W p) / W p$ was used, where $W s$ and $W p$ are the weights of the absorbed water and dried polymer, respectively.

\section{RESULTS AND DISCUSSION}

Amidation of DAA and DAA-PNAA core-shell type gels with Alkylamines

The heterogeneous reaction of DAA with IPA,

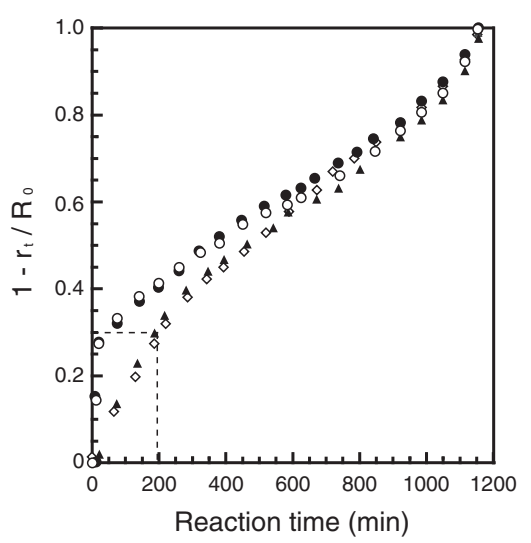

Figure 3. Typical amidation of a DAA gel and DAA-PNAA core-shell type gel with NPA or IPA; $(\mathbf{\Delta})$ reaction of DAA with NPA; $(\diamond)$ reaction of DAA with IPA; $(\bigcirc)$ reaction of $\mathbf{G - 5}$ with NPA; (๑) reaction of G-2 with IPA.

using TPP, proceeded via a mechanism that was similar to the unreacted-model $;{ }^{18}$ the amidation occurred on the surface of the unreacted DAA core, since DAA did not swelled in the solvent and the amidation reaction was very fast. The reaction from the surface gave PNIPA in the form of a core-shell type gel that consisted of an unreacted DAA core and a swelled shell (Figures 1 and 2). Based on these previous papers, ${ }^{14}$ the amidation of cylindrical DAA (length the same as the diameter; about $5.3 \mathrm{~mm}$ ) with alkylamines $\left(2.0 \mathrm{~mol} \mathrm{~L}^{-1}\right)$, such as NNA and IPA, was carried out in NMP, using TPP, at $80^{\circ} \mathrm{C}$. Typical disappearance rates for the core are shown in Figure 3. The rate was not affected by the type of alkylamine used, because the reaction rate was independent of the concentration. ${ }^{15 \mathrm{~b}}$ The core disappeared after about $1200 \mathrm{~min}$. The reaction of DAA with IPA and NPA gave PNIPA (PNIPA-1) and PNNPA (PNNPA-1) gels, respectively, when the core disappeared. The equilibrium swelling ratio for PNIPA gels prepared by several methods was measured in water over a wide temperature range (Figure 4). It is well known that the LCST in PNIPA was very sensitive to small amount of impurities. ${ }^{19}$ For example, copolymer gel of NIPA with $1 \mathrm{~mol} \%$ acrylic acid has a LCST of $35^{\circ} \mathrm{C}$, where the LCST of pure PNIPA gel is $32^{\circ} \mathrm{C} .{ }^{14 a}$ PNIPA-1 prepared by this method had LCSTs of approximately $31^{\circ} \mathrm{C}$ and showed much higher thermosensitivity than nonporous PNIPA-2 and porous PNIPA-3 prepared by radical polymerization. This results indicated that PNIPA-1 had high purity, and nearly quantitative amidation was achieved, when DAA was placed in NMP containing an excess amount of alkylamine $\left(2.0 \mathrm{~mol} \mathrm{~L}^{-1}\right)$ and TPP $\left(1.0 \mathrm{~mol} \mathrm{~L}^{-1}\right)$. The thickness of the shell layer was controlled by the reaction time. Core-shell type gels G-1-G-3 [DAA-PNNPA coreshell type gels, $r_{t} / R_{0}=0.10,0.70$, and 0.90] and G- 


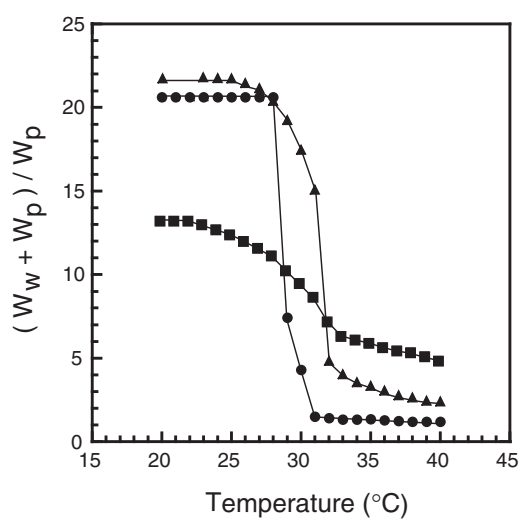

Figure 4. The equilibrium swelling ratio for PNIPA gels prepared by several methods in water as a function of temperature; (๑) PNIPA-1; (ム) PNIPA-2; (ם) PNIPA-3.

Table I. Synthesis of DAA-PNAA core-shell type gels by the first amidation of DAA with alkylamine ${ }^{\mathrm{a}}$

\begin{tabular}{clllrl}
\hline $\begin{array}{c}\text { Run } \\
\text { No. }\end{array}$ & Gel & Alkylamine & Solvent & $\begin{array}{r}\text { Reaction time } \\
(\min )\end{array}$ & $r_{t} / R_{0}$ \\
\hline 1 & PNNPA-1 & NPA & NMP & 1160 & 0 \\
2 & G-1 & NPA & NMP & 1100 & 0.10 \\
3 & G-2 & NPA & NMP & 200 & 0.70 \\
4 & G-3 & NPA & NMP & 55 & 0.90 \\
5 & PNIPA-1 & IPA & NMP & 1160 & 0 \\
6 & G-4 & IPA & NMP & 1100 & 0.10 \\
7 & G-5 & IPA & NMP & 200 & 0.70 \\
8 & G-6 & IPA & NMP & 55 & 0.90 \\
\hline
\end{tabular}

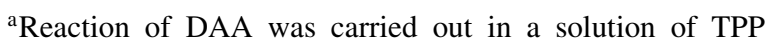
$\left(1.0 \mathrm{~mol} \mathrm{~L}^{-1}\right)$ and alkylamine $\left(2.0 \mathrm{~mol} \mathrm{~L}^{-1}\right)$ in NMP $(50 \mathrm{~mL})$ at $80^{\circ} \mathrm{C}$.

4-G-6 [DAA-PNIPA core-shell type gels, $r_{t} / R_{0}=$ $0.10,0.70$, and 0.90$]$ were synthesized by the first amidation of DAA with the corresponding alkylamine in NMP, using TPP, at $80^{\circ} \mathrm{C}$ for 1100,200 , and 55 min, respectively (Table I). The resulting DAAPNAA core-shell type gels were washed with methanol in a Soxhlet extractor. They were dried in vacuo at $60^{\circ} \mathrm{C}$ to constant weight. The second amidation of the dried core-shell type gels with another alkylamine was carried out for $24 \mathrm{~h}$ under similar conditions to the first amidation. After rapid initial swelling of the amidated shell layer, the second amidation, which showed similar characteristics to the first amidation, occurred (Figure 3). The difference in the time required for complete disappearance of the unswollen core of the former compared with the latter was negligible, because the reaction proceeded under diffusion control of the unreacted-core model. ${ }^{14 \mathrm{~b}, 18}$ The amidation of G-1-G-6 gave the corresponding PNAA(2)-PNAA(1) core-shell type gels, GC-1-GC6, respectively. The results and conditions are summarized in Table II.
Table II. Synthesis of PNAA(2)-PNAA(1) core-shell type gels by the second amidation of DAA-PNAA core-shell type gels with various alkylamines ${ }^{\mathrm{a}}$

\begin{tabular}{rcccc}
\hline $\begin{array}{c}\text { Run } \\
\text { No. }\end{array}$ & $\begin{array}{c}\text { PNAA(2)-PNAA(1) } \\
\text { core-shell } \\
\text { type gel }\end{array}$ & Alkylamine & $\begin{array}{c}\text { DAA-PNAA } \\
\text { core-shell } \\
\text { type gel }\end{array}$ & $r_{t} / R_{0}$ \\
\hline 9 & GC-1 & IPA & G-1 & 0.10 \\
10 & GC-2 & IPA & G-2 & 0.70 \\
11 & GC-3 & IPA & G-3 & 0.90 \\
12 & GC-4 & NPA & G-4 & 0.10 \\
13 & GC-5 & NPA & G-5 & 0.70 \\
14 & GC-6 & NPA & G-6 & 0.90 \\
\hline
\end{tabular}

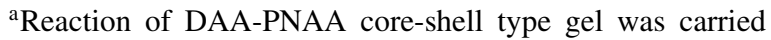
out in a solution of TPP $\left(1.0 \mathrm{~mol} \mathrm{~L}^{-1}\right)$ and alkylamine $(2.0$ $\left.\mathrm{mol} \mathrm{L}{ }^{-1}\right)$ in NMP at $80^{\circ} \mathrm{C}$ for $24 \mathrm{~h}$.

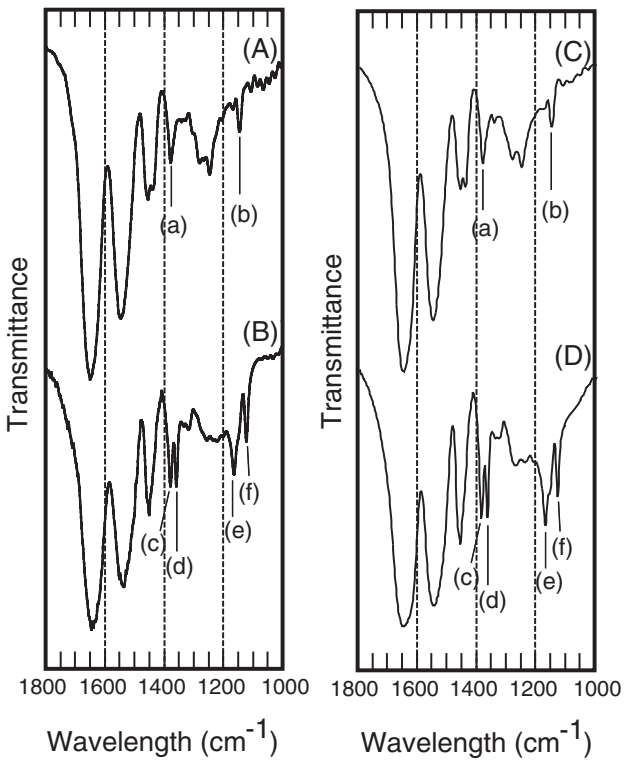

Figure 5. IR spectra (KBr) of PNAA gels; (A) PNNPA core in GC-5; (B) PNIPA shell in GC-5; (C) PNNPA ${ }^{7 \mathrm{c}}$ gel prepared by radical polymerization of $N$ - $n$-propylacrylamide; (D) PNIPA-2.

\section{Characterizations of the Core-Shell Type Gel Ob- tained by the Second Amidation}

Typical IR spectra of GC-5, resulting from the amidation of a DAA-PNIPA core-shell type gel $\left[r_{t} / R_{0}=\right.$ 0.70] with NPA, are shown in Figure 5. The PNIPA shell (B) and PNNPA core (A) of the gel showed strong absorption peaks at $3300 \mathrm{~cm}^{-1}(\mathrm{~N}-\mathrm{H}$, stretching), 1650 and $1545 \mathrm{~cm}^{-1}$ (amide I and amide II) with no absorption occurring at either $1710 \mathrm{~cm}^{-1}(\mathrm{C}=\mathrm{O}$ of carboxylic acid) or $1755 \mathrm{~cm}^{-1}$ ( $\mathrm{C}=\mathrm{O}$ of phenyl ester). Neutralization analysis showed that the amidated gels contained no carboxylic acid groups. The shell layer and core of the core-shell type gel showed absorption peaks characteristic of PNIPA at each of 1385 (c), 1368 (d), 1173 (e) and 1131 (f) $\mathrm{cm}^{-1}$ and of PNNPA at each of 1384 (a) and 1153 (b) $\mathrm{cm}^{-1}$; the absorption 
spectra were clearly consistent with those of PNIPA-2 (D) and PNNPA $^{7 \mathrm{cc}}$ (C) gels prepared by the radical polymerization of the corresponding monomers respectively, as well as PNIPA-1 and PNNPA-1. ${ }^{15 \mathrm{~d}}$ These results indicated that the second amidation of DAA-PNAA core-shell type gels with an alkylamine was nearly quantitative, giving the corresponding PNAA(2)-PNAA(1) core-shell type gels. Since unreacted DAA cores in the core-shell type gels can react with various reagents, they are useful for their chemical modification and the synthesis of a wide variety of core-shell type gels.

Thermal Swelling/De-swelling Behavior of the coreshell type gels

In the synthesis of the PNAA(2)-PNAA(1) coreshell type gels, attention was paid to the thermal swelling/de-swelling behavior of PNNPA-1 and PNIPA-1 gels. PNNPA-1 and PNIPA-1 gels had LCSTs of approximately 21 and $31{ }^{\circ} \mathrm{C}$, respectively, and the difference in the equilibrium swelling ratios of PNNPA-1 and PNIPA-1, at temperatures below and above the LCST, was negligible. ${ }^{14 \mathrm{~d}}$ Thermal swelling/de-swelling behavior of PNNPA-1 and PNIPA-1 gels was divided into three regions: 1$)$ at a lower temperature region $\left(<21^{\circ} \mathrm{C}\right)$, PNNPA-1 and PNIPA-1 swelled, 2) at a middle temperature region (between 21$31^{\circ} \mathrm{C}$ ), PNNPA-1 and PNIPA-1 de-swelled and swelled, respectively, and 3) at a higher temperature region $\left(>31^{\circ} \mathrm{C}\right.$ ), both PNNPA-1 and PNIPA-1 deswelled. The differences among the three regions were so large that the properties of PNNPA-PNIPA and PNIPA-PNNPA core-shell type gels would be expected to change dramatically in response to changing temperatures. The swelling/de-swelling behavior of PNAA(2)-PNAA(1) core-shell type gels was measured in water at temperatures $\left(15,25\right.$, and $\left.35^{\circ} \mathrm{C}\right)$ in the three regions.

When dried GC-3, PNIPA-PNNPA core-shell type gels $\left(r_{t} / R_{0}=0.90\right)$ were placed in water at $15^{\circ} \mathrm{C}$, the de-swelled gels began to swell from the surface. The swelling behavior in water for $t$ min was described using the expression, $R_{t}^{\prime} / R_{D}^{\prime}$, where $R_{D}^{\prime}$ and $R_{t}^{\prime}$ were the external radii of the dried gel and swelled in water for $t$ min, respectively (Figure 6). The gel swelled slowly, but maintained its cylindrical shape, and reached the equilibrium swelling ratio after $50 \mathrm{~h}$; no significant swelling occurred at temperatures above the LCST of PNIPA. The swelling behavior of the PNIPA-PNNPA core-shell type gels was nearly the same as that observed for PNNPA-1 and PNIPA-1 gels at $15^{\circ} \mathrm{C}$. A boundary between the two layers was not observed in the swollen core-shell type gel because there was hardly any difference of optical properties between them. The thermosensitive

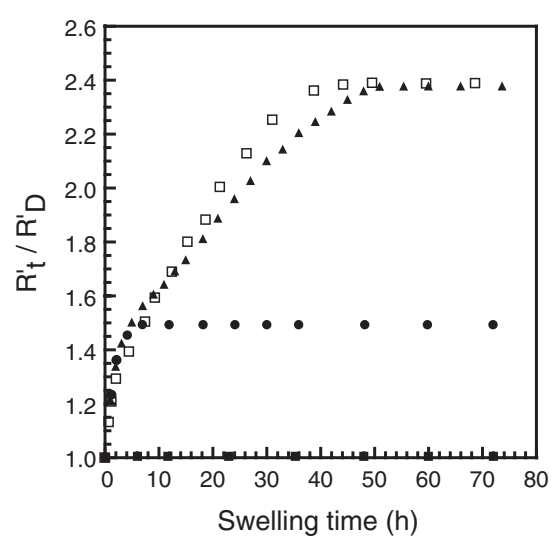

Figure 6. Swelling of PNIPA-1 gel and GC-3 in water; $(\square)$

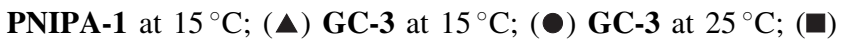
GC-3 at $35^{\circ} \mathrm{C}$.

PNNPA shell layer change from being hydrophilic to hydrophobic at $25^{\circ} \mathrm{C}$ and the equilibrium swelling ratio was reached at $2 \mathrm{~h}$. The equilibrium swelling ratio $\left(R_{t}^{\prime} / R_{D}^{\prime}\right)$ was 1.5 at $25^{\circ} \mathrm{C}$ compared with 2.4 at $15^{\circ} \mathrm{C}$. Previous papers ${ }^{14 \mathrm{~b}, \mathrm{~d}}$ reported that the hydrophobic PNNPA or PNIPA shell layer of the PAA-PNAA core-shell type gels functioned as a permeability barrier to water when the gel was placed in water at temperatures higher than the LCST. The PNIPA-PNNPA core-shell type gel swelled only slightly, and the dense shell layer suppressed swelling of the core. In PNNPA-PNIPA core-shell type gels, only the PNIPA shell layer swelled in water at $25^{\circ} \mathrm{C}$. Therefore, the swelling of the cores in the PNAA(2)-PNAA(1) core-shell type gels was affected by the hydrophilic/ hydrophobic properties of the shell layers, where the shell swelled independently when the water temperature is lower than the LCST.

De-swelling of the gels swelled in water at $15^{\circ} \mathrm{C}$ was carried out at various temperatures above the LCST of PNNPA. When swelled gels were immersed in water at $25^{\circ} \mathrm{C}$, the $R_{t}^{\prime} / R_{0}^{\prime}$ values, where $R_{0}^{\prime}$ and $R_{t}^{\prime}$ are the radii diameters of the gel stored in water at $50{ }^{\circ} \mathrm{C}$ and de-swelled in water for $t \mathrm{~min}$, respectively, decreased since only the PNNPA regions shrunk. The PNNPA-1 gel rapidly reached the equilibrium swelling ratio (Figure 7). However, the de-swelling rate for the PNNPA shell in GC-2 $\left(r_{t} / R_{0}=0.70\right)$ and the core in GC-5 $\left(r_{t} / R_{0}=0.70\right)$ was lower than that of PNNPA-1. De-swelling of the PNNPA core and shell layer appeared to be structurally inhibited by the swollen PNIPA shell layer and core, respectively. Especially, the de-swelling rate for GC-5 was low because water must diffuse from the core to surface. When the core-shell type gels and PNIPA stored at $25^{\circ} \mathrm{C}$ were placed in water at $35^{\circ} \mathrm{C}$, the gels shrunk again due to the de-swelling of the PNIPA regions. After $1200 \mathrm{~min}$, all core-shell type gels and the 


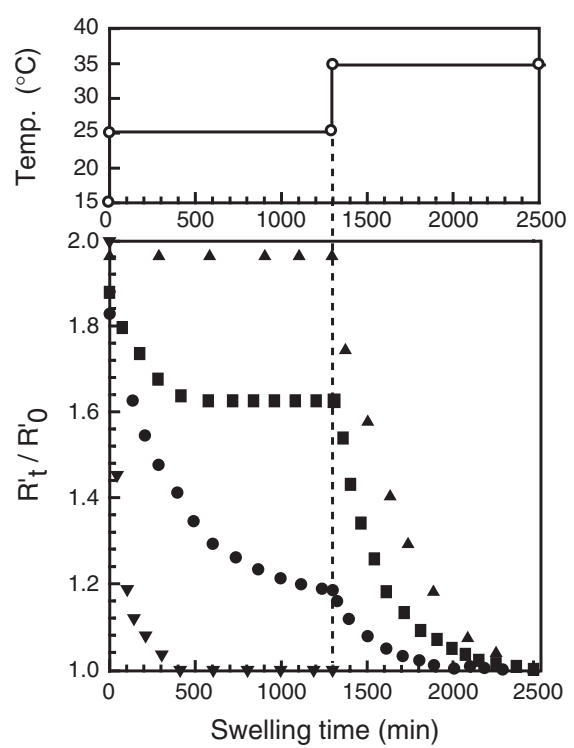

Figure 7. De-swelling of gels previously swelled in water in response to stepwise changes in temperature; $(\boldsymbol{\nabla})$ PNNPA-1;

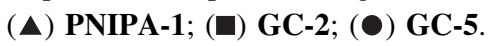

PNIPA-1 gel reached the original size of the gels stored in water at $50{ }^{\circ} \mathrm{C}$. Therefore, the de-swelled PNNPA shell layer in GC-2 did not function effectively as a permeability barrier to water during deswelling, and the two-step de-swelling of the coreshell type gels, due to the independent de-swelling of the core and shell in response to stepwise temperature changes, was observed. In addition, the thin shell layers were not burst when the stepwise temperature changes were repeated.

Typical images of de-swelling of GC-4, a PNNPAPNIPA core-shell type gel $\left[r_{t} / R_{0}=0.10\right]$, are shown in Figure 8. The PNIPA shell in GC-4 swelled and the PNNPA core de-swelled in water at $25^{\circ} \mathrm{C}$. When the gel was immersed in water at $40^{\circ} \mathrm{C}$, the surface

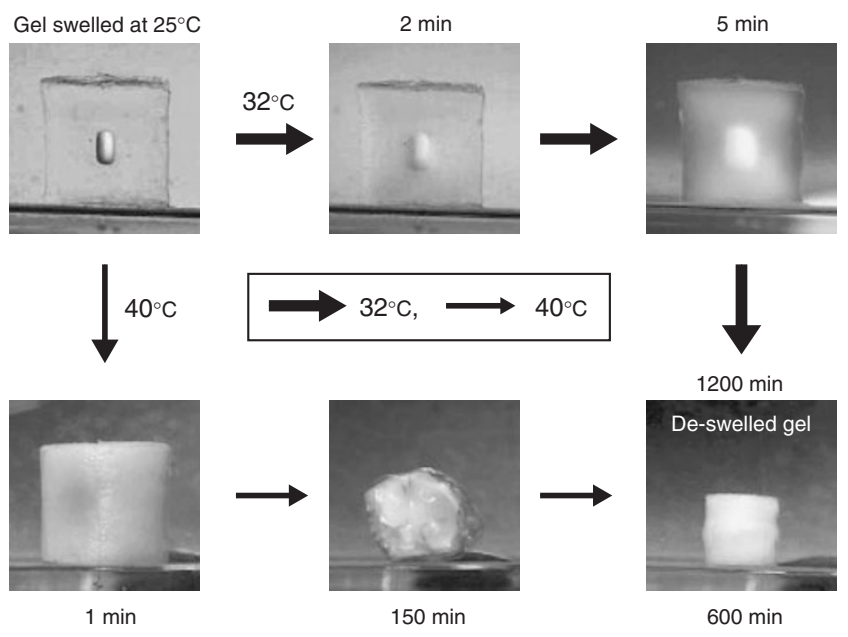

Figure 8. Typical pictures of de-swelling of GC-4 previously swelled in water at 32 and $40^{\circ} \mathrm{C}$.

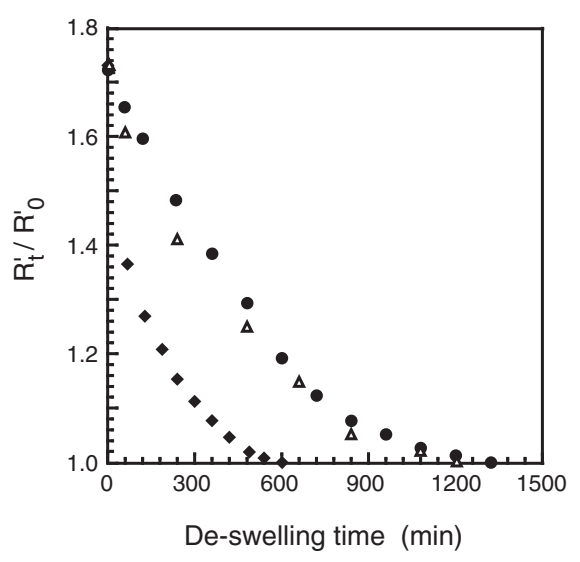

Figure 9. De-swelling of GC-4 previously swelled in water at various temperatures; (๑) $25 \rightarrow 32{ }^{\circ} \mathrm{C} ;(\triangle) 25 \rightarrow 35^{\circ} \mathrm{C}$; (•) $25 \rightarrow 40^{\circ} \mathrm{C}$.

was heated locally, and a dense surface skin layer was produced. The shrinkage force was so strong that water was ejected from the gel. Although the skin layer functioned as a permeability barrier to water, the de-swelling rate at $40^{\circ} \mathrm{C}$ was higher than those observed at 32 and $35^{\circ} \mathrm{C}$ (Figure 9). This result suggested that the shrinkage force was so strong that water was ejected from the gel. The rapid shrinking was well-known as a squeeze effect of PNIPA gel,,${ }^{19}$ forcing water from the gel. On the other hand, the clouding of the PNIPA shell layer occurred near the PNNPA core, and then the entire gel turned milky at 32 and $35^{\circ} \mathrm{C}$ slightly higher than the LCST, where the swelled PNIPA-1 became uniformly milky. Similar phenomenon was not observed in the de-swelling of PNNPA shell layers and cores in the PNAA(2)PNAA(1) core-shell type gels. The local shrinking might be attributed to a slight composition gradient in the shell layer and a neighboring effect of hydrophobic properties of the cores. The local shrinking was observed in a matter of minutes, and the deswelling rate was the same as that of PNIPA-1 gel (Figure 7). Therefore, the de-swelling of shell layers and cores in the PNAA(2)-PNAA(1) core-shell type gels was hardly affected by the local shrinking, and occurred almost independently in response to the temperature changes. The shell layers showed almost the same thermosensitive behavior as those in the corresponding PAA-PNAA core-shell type gels, ${ }^{14 b, d}$ which showed on-off chemical release characteristics in response to stepwise temperature changes. However, the thermal swelling/de-swelling behavior of the PNAA(2)-PNAA(1) core-shell type gels can be controlled more multiply than that of PAA-PNAA coreshell type gels, since the core also showed thermosensitivity. This behavior may be useful for design of fine functional polymers. 
Preparation of Semi-cylindrical Double-layer Gels

The resulting cylindrical PNAA(2)-PNAA(1) coreshell type gel cannot be markedly deformed by swelling/de-swelling because of the axial symmetry. Cylindrical PNIPA-PNNPA and PNNPA-PNIPA coreshell type gels $\left(r_{t} / R_{0}=0.70,2 R_{D}^{\prime}: 4.2 \mathrm{~mm}\right.$, length: about $16 \mathrm{~mm}$ ) were prepared by two-step amidation of the corresponding long DAA. The core-shell type gels were cut laterally approximately $2 \mathrm{~mm}$ from the edge and into two halves, resulting in semi-cylindrical, long, double-layer gels $\mathbf{G C}^{\prime}-\mathbf{2}$ and $\mathbf{G C}^{\prime}-\mathbf{5}$ (Figure 2). The semi-cylindrical gels obtained could be bent markedly in response to stepwise temperature changes since they were not symmetric with respect to the axis.

Thermal Swelling/De-swelling Behavior of Semi-cylindrical Double-layer Gels

The semi-cylindrical dried $\mathbf{G C}^{\prime}$-2 (A) $\left(2 R_{D}^{\prime}: 4.2\right.$ $\mathrm{mm}$, length: $12 \mathrm{~mm}$ ), containing a PNNPA shell layer and PNIPA core, slowly swelled in water at $15^{\circ} \mathrm{C}$, but maintained its semi-cylindrical shape, reaching the equilibrium swelling ratio after $40 \mathrm{~h}$ (Figure 10). The swollen gel (B) de-swelled slowly in water at $35^{\circ} \mathrm{C}$ (Figure 11). The swelling/de-swelling behavior was the same as those of the PNIPA-1 and PNNPA-1 gels. On the other hand, when the swollen gel (B) was immersed in water at $25^{\circ} \mathrm{C}$, the transparent PNNPA shell layer immediately turned milky and shrank independently of the core, curling towards the shell side. After $2 \mathrm{~h}$, the gel (C) was markedly bent and was inside-out. Although the shape of the bent gel was extremely distorted, the destruction on the boundary hardly occurred because it had a defined structurea continuous network and a boundary between both layers. As the water temperature was raised from 25 to $35^{\circ} \mathrm{C}$, the swelled core of the bent gel (C) slowly shrunk. After $20 \mathrm{~h}$, the de-swelled gel (D) was almost the same size as the original dried gel (A). However, direct change from the original gel to the opaque gel
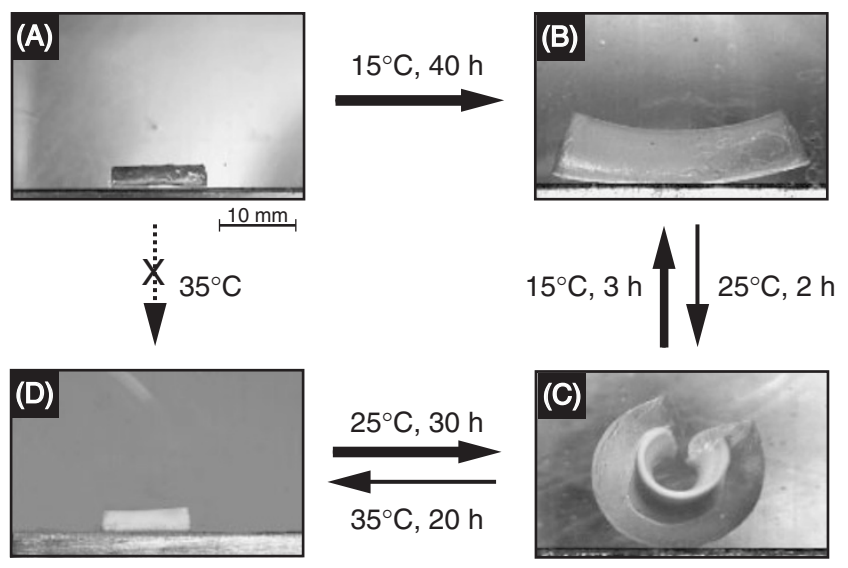

Figure 10. Typical pictures of swelling/de-swelling of $\mathbf{G C}^{\prime} \mathbf{- 2}$ in water; (A) dried gel; (B) swelled gel at $15^{\circ} \mathrm{C}$; (C) bent gel at $25^{\circ} \mathrm{C}$; (D) deswelled gel at $35^{\circ} \mathrm{C}$.

(D) did not occur when the original gel was stored in water at $35^{\circ} \mathrm{C}$ for a long time. When the water temperature was lowered from 35 to 25 and to $15^{\circ} \mathrm{C}$ in a stepwise fashion, the de-swelled gel (D) was transformed into the swelled gel (B) through the bent gel (C). The deformation between the swelled gel (B) and the bent gel (C) was faster than that between the de-swelled gel (D) and the bent gel (C) because the shell layer was thinner than the core. Deformation induced by heating was slightly faster than that caused by cooling. The swelled and de-swelled shapes of semi-cylindrical $\mathbf{G C}^{\prime}-\mathbf{5}$ were the same as those of GC'-2 in water at 15 and $35^{\circ} \mathrm{C}$, respectively. The PNIPA shell swelled and the PNNPA core shrunk at $25^{\circ} \mathrm{C}$; however, the gel $\left(\mathrm{C}^{\prime}\right)$ did not bend to the core side because the semi-cylindrical structure inhibited axial shrinking of the core sufficiently, such that radial shrinking preferentially occurred. These deformations occurred reversibly in response to the stepwise temperature changes, even though the deformation of GC'-2 was so large. However, the shell layer of $\mathbf{G C}^{\prime}-2$ peeled off gradually, although both layers com-

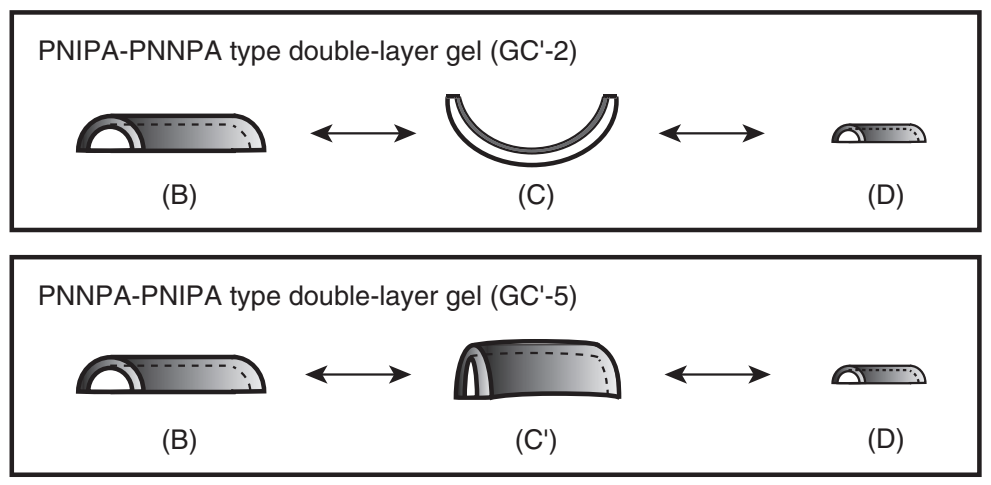

Figure 11. Deformation of semi-cylindrical, double-layer gels in response to stepwise changes in temperature; (B) swelled gel at $15^{\circ} \mathrm{C}$; (C) and $\left(\mathrm{C}^{\prime}\right)$ bent gel at $25^{\circ} \mathrm{C}$; (D) deswelled gel at $35^{\circ} \mathrm{C}$. 
bined with each other by a continuous network when the stepwise temperature changes were repeated. The differences in deformations between $\mathbf{G} \mathbf{C}^{\prime}-\mathbf{2}$ and $\mathbf{G} \mathbf{C}^{\prime}$ 5 are interesting in terms of the design of novel functional polymers for use as actuators and temperature sensors.

\section{CONCLUSION}

1. The first amidation of DAA with alkylamines proceeded nearly quantitatively at $80^{\circ} \mathrm{C}$ in the presence of TPP to give the corresponding DAA-PNAA core-shell type gels. The thickness of the shell layer was controlled by the reaction time. PNAA(2)-PNAA(1) core-shell type gels were prepared by the second amidation of DAA-PNAA core-shell type gel with another alkylamine under the similar conditions as the first amidation.

2. Although PNNPA and PNIPA differed in LCST, the difference between them in equilibrium swelling ratio at temperatures below and above the transition was negligible.

3. The swelling of the cores in the PNAA(2)PNAA(1) core-shell type gels was affected by the hydrophilic/hydrophobic properties of the shell layers, where the shell swelled independently when the water temperature is lower than the LCST.

4. The de-swelling of shell layers and cores in the PNAA(2)-PNAA(1) core-shell type gels occurred almost independently in response to the temperature changes.

5. The semi-cylindrical, double-layer gels were prepared by laterally cutting the cylindrical PNIPAPNNPA and PNNPA-PNIPA approximately $2 \mathrm{~mm}$ from the edge and by cutting the cylinders into halves.

6. The semi-cylindrical, double-layer gels prepared from PNIPA-PNNPA core-shell type gels were markedly bent in water at temperatures between the LCSTs of PNIPA and PNNPA.

Acknowledgment. This work was supported by a grant from the Ministry of Education, Science and Culture of Japan (No. 18550195), which is gratefully acknowledged.

\section{REFERENCES}

1. S. Ito, Kobunshi Ronbunshu, 46, 437 (1989).

2. a) M. Heskins and J. E. Guillet, J. Macromol. Sci. Chem., 2,
1441 (1968).

b) S. Hirotsu, Y. Hirokawa, and T. Tanaka, J. Chem. Phys., 87, 1392 (1987).

c) S. Fujishige, K. Kubota, and I. Ando, J. Phys. Chem., 93, 3311 (1989).

3. a) R. F. S. Freitas and E. L. Cussler, Chem. Eng. Sci., 42, 97 (1987).

b) W. Cai and R. B. Gupta, Ind. Eng. Chem. Res., 40, 3406 (2001).

4. Y. Seida and Y. Nakano, J. Chem. Eng. Jpn., 29, 767 (1996).

5. L. C. Dong and A. S. Hoffman, J. Controlled Release, 15, 141 (1990).

6. T. G. Park and A. S. Hoffman, J. Biomed. Mater. Res., 24, 21 (1990).

7. a) R. Pelton, Adv. Colloid Interface Sci., 85, 1 (2000).

b) T. Iizawa, H. Taketa, M. Maruta, T. Ishido, T. Gotoh, and

S. Sakohara, J. Appl. Polym. Sci., 104, 842 (2007).

c) T. Iizawa, T. Ishido, T. Gotoh, and S. Sakohara, Polym. J., 39, 18 (2007).

8. a) B. G. Kabra and S. H. Gehrke, Polym. Commun., 32, 322 (1991).

b) T. Gotoh, Y. Nakatani, and S. Sakohara, J. Appl. Polym. Sci., 69, 895 (1998).

9. R. Yoshida, K. Uchida, Y. Kaneko, K. Sakai, A. Kikuchi, Y. Sakurai, and T. Okano, Nature, 374, 240 (1995).

10. T. Okano, N. Yamada, H. Sakai, and Y. Sakurai, J. Biomed. Mater. Res., 27, 1243 (1993).

11. a) F. Higashi, J. Synth. Org. Chem. Jpn., 47, 995 (1989). b) M. Ueda, J. Synth. Org. Chem. Jpn., 48, 144 (1990).

12. M. Akashi, S. Nakano, and A. Kishida, J. Polym. Sci., Part A: Polym. Chem., 34, 301 (1996).

13. a) T. Iizawa and F. Matsuda, Polym. J., 30, 155 (1998).

b) F. Matsuda, S. Miyamato, and T. Iizawa, Polym. J., 31, 435 (1999).

c) F. Matsuda, N. Matsuno, and T. Iizawa, Kobunshi Ronbunshu, 55, 439 (1998).

d) T. Iizawa, S. Miyamoto, and S. Sugano, Kobunshi Ronbunshu, 57, 715 (2000).

14. a) T. Iizawa, N. Matsuno, M. Takeuchi, and F. Matsuda, Polym. J., 31, 1277 (1999).

b) T. Iizawa, N. Matsuno, M. Takeuchi, and F. Matsuda, Polym. J., 34, 63 (2002).

c) T. Iizawa, Y. Matsura, K. Hashida, and Y. Onohara, Polym. J., 35, 815 (2003).

d) T. Iizawa, Y. Matsuura, and Y. Onohara, Polymer, 46, 8098 (2005).

15. a) T. Iizawa, T. Morimoto, T. Yamaguchi, and S. Kato, Polymer, 45, 5077 (2004).

b) T. Iizawa, K. Nakao, T. Yamaguchi, and M. Maruta, Polymer, 46, 1834 (2005).

16. H. Kawaguchi and S. Muroi, in "Polymer Colloid," Kyoritsu Shuppan Inc., Tokyo, 1990.

17. N. Kayaman, D. Kazan, A. Erarslan, O. Okay, and B. M. Baysal, J. Appl. Polym. Sci., 67, 805 (1998).

18. S. Yagi and T. Kunii, Kogyo Kagaku Zashi, 56, 131 (1953).

19. T. Okano, Y. H. Bae, H. Jacobs, and S. W. Kim, J. Controlled Release, 11, 255 (1990). 